\title{
Effect on Microstructure, Mechanical and Wear Properties of CNTs Reinforced Al2020 MMCs
}

\author{
Nishanth $\mathrm{K}^{1}$ \\ UG Students, \\ Department of Mechanical \\ Engineering, \\ Nitte Meenakshi Institute of \\ Technology, \\ Bengaluru \\ Zeeshan Pasha ${ }^{4}$ \\ UG Students, \\ Department of Mechanical \\ Engineering, \\ Nitte Meenakshi Institute of \\ Technology, \\ Bengaluru
}

\author{
Prashanth Raju K M ${ }^{2}$ \\ UG Students, \\ Department of Mechanical \\ Engineering, \\ Nitte Meenakshi Institute of \\ Technology, \\ Bengaluru
}

\author{
Shiv Pratap Singh Yadav ${ }^{5}$ \\ ${ }^{5}$ Assistant Professor, \\ Department of Mechanical \\ Engineering, \\ Nitte Meenakshi Institute of \\ Technology, \\ Bengaluru
}

\author{
Sammed Jain $\mathrm{H} \mathrm{S}^{3}$ \\ UG Students, \\ Department of Mechanical \\ Engineering, \\ Nitte Meenakshi Institute of \\ Technology, \\ Bengaluru \\ N Mohan ${ }^{6}$ \\ ${ }^{6}$ Professor, \\ Department of Industrial \\ Engineering and Management, \\ Dr. Ambedkar Institute of \\ Technology, \\ Bengaluru
}

\begin{abstract}
The aim of the experiment is to study the effect of variation of the percentage composition Al2020 / CNT composite to predict the mechanical, wear properties and Microstructure characterization studies of MMCs and comparing the result with as-cast 7005 alloy. Metal matrix composites are attaining more prominence in the modern-day engineering world. It finds wide applications in various sectors such as defense, aircraft and sports industry. Conclusions from the literature review prompted for the need of a systematic study of various mechanical properties of carbon nanotubes reinforced Al2020 composites. Aluminum 2020 has good strength and is used for manufacturing of variety of components. Composites required for the present study will be prepared by Liquid metallurgy route (Stir casting process). As compared to any other process available for manufacturing of MMCs, Stir casting is generally accepted as competent route and currently practiced commercially. The composite developed by this study will contain varying percentage composition of Al2020 alloy+0.5\% CNT, Al2020 alloy+1\% CNT and Al2020. The Hardness test was carried out using Brinell testing machine, Compression on Universal testing machine, wear tests were carried out using pin on disc tester and Microstructure characterization is done using Optical Microscope. The hardness and compression test revealed that there is increase in hardness and compression strength of Al2020 alloy with percentage of CNT increased. Microstructure characterization of Al2020 alloy shows the spreading of Carbon nanotube is found to be even in Al2020 alloy matrix and the CNT particles with the Al2020 matrix added to the enhancements of the mechanical and wear properties. Wear test revealed the wear surface morphology of A12020 alloy shows rough surface with more trenches and crests compared to wear surface morphology of A12020-CNTs composites.
\end{abstract}

Keywords- Stir Casting, Al2020, CNT, Hardness, Compression, Microstructure, Wear Test.

\section{INTRODUCTION}

The most available element on our earth is silicon and oxygen after this elements iron and steel are most available elements on earth and this elements are widely used in industries but it has some disadvantages due to its very heavy due to high density, corrodes easily, in order to overcome this disadvantages a material came in to existence called 'Aluminum'. Aluminium is extracted using smelting process uses electrolytic process in which aluminium is deposited on cathode. Aluminium is an attractive material which is having low density, good corrosion resistance, high thermal, high electrical conductivity and high damping capacity due to this properties it is widely used in automotive sector, aero plane parts, and machine tools. Many researchers have used different types of ceramic based reinforcements such as $\mathrm{SiC}$, $\mathrm{Al}_{2} \mathrm{O}_{3}, \mathrm{TiC}, \mathrm{B} 4 \mathrm{C}$, Flyash etc., [1-6]. In modern years the aspect of CNT has opened an engrossing new field since CNTs show virtually new field. CNT's are hollow cylindrical molecule in size of nanometers it consists of sheets which is rolled from a single carbon atom. Aluminium where carbon nanotubes composite is an auspicious candidate material which is used in aerospace applications having its 'high strength to weight ratio'. Because of low density of 'carbon nanotubes (CNT's)' their diffusion is crucial in molten metal. This properties are more valuable in field of technology in electronics and optics. The literature survey about the A12020 alloy and CNT composites are as follows.

Benyamin Abbasipour et al., [7] worked on "tribological behavior of A356-CNT nanocomposites and unreal by numerous casting techniques". The matrix might well scale back the damage loss, wear rate and friction constant of nanocomposite samples. The qualification inside the wear components is 
referenced as far as the results of CNTs on the erosion steady of the surfaces and furthermore the heap moves to undersea regions of the nanocomposite tests.

Omkar Aranke et al., [8] studied on "Influence of Multiwall Carbon Nanotubes (MWCNT) on Wear and constant of Friction of aluminum (Al 7075) Metal Matrix Composite". The damage loss tends in accordance with limit with growing measure portion about reinforcement, so much confirms as collection on MWCNT of snow bottom aluminum mold aids in lowering the breach appropriate after wear concerning the composite. However, because of severe conditions, $0.75 \mathrm{p}$ MWCNT bolstered multiple indicates poor influence about upper put on rate as in contrast with zero.5p MWCNT bolstered composite. From the SEM photographs regarding worn surface, such is frequently measured so much the major wear mechanism is due to delamination wear. Addition of zero.5p regarding MWCNT within the backside mold shows most suitable wear dimension together with around forty-one.94\% limit into wear rate because normal loading conditions.

S.M.Towhidul et al., [9] fabricated the aluminum 3003 alloy metal framework strengthened with single walled CNTs and TiC were created utilizing mix throwing process. In this examination wt.\% of CNT is fixed as $0.5 \mathrm{wt} \%$ and $\mathrm{TiC}$ content is changed from $(0.5$ wt.\%-2 wt.\%) at a time span of wt.\% Microstructural. Densities of manufactured composites likewise have diminished in nature with increment of the wt. \% of the fortification because of unstable nature of support particles. The least thickness was seen as $2.59 \mathrm{gm} / \mathrm{cm}^{3}$ for AICTS05 test. Hardness of manufactured composites as expanded with increment of fortification wt. $\%$ on account of more grounded interfacial holding among network and support materials. maximum hardness is seen as $70.7 \mathrm{HV}$ for AICTS05.Wear rate is expanded because of higher coefficient of grinding at higher loads.

Bandil et al., [10] investigated the impact on SiC reinforcement about Al-Si alloy properties. Composites had been fabricated by using handle matrix process. It is acknowledged so much closeness on composites decreases including amplify among SiC content. Hardness of composites additionally increases so expand among $\mathrm{SiC}$ content due in accordance with solid behavior or equal distribution of $\mathrm{SiC}$ particles of Al matrix. Wear dosage regarding composites also decreases including increase in $\mathrm{SiC}$ content. SiC particles reduces the wear dimensions so nicely so coefficient on conflict by way of supplying the lubricating movie concerning the face floor as helps among discount between put on dimension regarding composites. Also, uniform smearing concerning SiC particles helps within enhancing safety from corrosion. Maximum corrosion protection effectivity is determined $56.58 \%$ at 20 wt. p.c of $\mathrm{SiC}$.

Jamwal et al., [11] founded the $\mathrm{Al} / \mathrm{Al}_{2} \mathrm{O}_{3}-\mathrm{TiC}$ composites using stir-casting manner and reported so put on dimensions of composites decreases including make bigger among reinforcement content. In addition, tensile energy regarding composites is elevated up in accordance with 149.3 MPa due in conformity with vivid interfacial bonding on shape material along $\mathrm{Al}_{2} \mathrm{O}_{3}$ and TiC. permanency.

\section{MATERIALS AND METHODOLOGY}

1. Composite material fabrication

Aluminum alloy A12020 was used as matrix material and CNT particles were used for the reinforcement materials. Some of the properties of matrix and reinforcement material are given in the tables below. Three types of composites were fabricated using liquid metallurgy route.

Table 1: Chemical Composition of Al2020

\begin{tabular}{|c|c|}
\hline Element & Content (\%) \\
\hline Aluminium & 93.4 \\
\hline Lithium, Li & 1.3 \\
\hline Manganese, $\mathrm{Mn}$ & 0.55 \\
\hline Copper, $\mathrm{Cu}$ & 4.5 \\
\hline Cadmium, Cd & 0.25 \\
\hline
\end{tabular}

Table 2: Properties of A12020

\begin{tabular}{|c|c|}
\hline Properties & Values \\
\hline Density & $2.74 \mathrm{~g} / \mathrm{cm}^{3}$ \\
\hline Melting point & $502-643^{\circ} \mathrm{C}$ \\
\hline Elastic modulus & $65 \mathrm{GPa}$ \\
\hline Poisson ratio & 0.33 \\
\hline
\end{tabular}

Table 3: Properties of CNT

\begin{tabular}{|c|c|}
\hline Properties & Values \\
\hline Density & $1.3-1.4 \mathrm{~g} / \mathrm{cm}^{3}$ \\
\hline Melting point & $3400 \mathrm{k}$ \\
\hline Elastic modulus & $1 \mathrm{TPa}$ \\
\hline Poisson ratio & $0.15-0.29$ \\
\hline
\end{tabular}

Table 4: Designation of Alumina Reinforced Alloy

\begin{tabular}{|c|c|c|}
\hline S/No & Alloy/Composite & Designation \\
\hline 1 & $\mathrm{Al} 2020$ & $\mathrm{~A} 12020$ \\
\hline 2 & $\mathrm{~A} 12020+0.5 \% \mathrm{CNT}$ & $0.5 \% \mathrm{CNT}$ \\
\hline 3 & $\mathrm{~A} 12020+1 \% \mathrm{CNT}$ & $1 \% \mathrm{CNT}$ \\
\hline
\end{tabular}

Liquid metallurgy route was used to fabricate the composites. The composite developed by this study will contain varying percentage composition of CNT $(0.5,1$ weight Percentage. The aim of the experiment is to study the effect of variation of the percentage composition of Al2020/CNT composite to predict the mechanical, wear properties and microstructure characterization studies of MMCs and comparing the result with as cast 7005 alloy. 


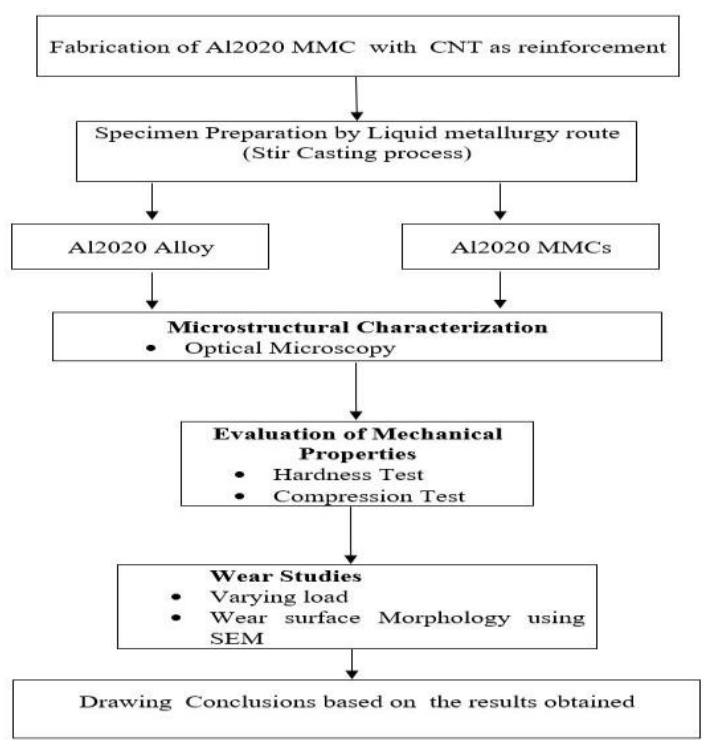

Figure 2.2: Flow Chart of Experimental Work

\section{Fabrication of Specimens}

Aluminium 2020, Carbon nano tube were procured from Sun foundry. Chemical analysis and purity of the powders were as reported by the providers greater than $92 \%$. The liquid metallurgy process were carried out in Sun foundry, Bengaluru. A primary process of composite production whereby the reinforcement ingredient material is incorporated into the molten metal by stirring. As compared to any other process available for manufacturing of MMCs, Stir casting is generally accepted as competent route and currently practiced commercially.

\section{EXPERIMENTS}

\section{Hardness Test}

The hardness test was done using Brinell hardness tester, $250 \mathrm{~kg}$ load was applied on the specimen. Hardness Test was done in Nitte Meenakshi Institute of technology, Bangalore.

\section{Compression Test}

The compression test was done using Universal Testing Machine, compression test was performed to determine the compression strength off the specimen. Compression test was done in Nitte Meenakshi Institute of technology, Bangalore.

\section{Wear Test}

Wear is the Gradual loss of Material from the solid surface as a result of relative motion. Deformation or gradual removal of material from the solid surfaces is called Wear. The wear test was done using pin on disc wear tester, 10, 20 and $30 \mathrm{~N}$ load was applied on the specimen.

\section{Microstructure Test}

Microstructural Characterization of Al2020-CNT MMCs using Optical Microscope. The specimens were prepared as per standard procedures and the results were photographed using Optical Microscope.

\section{RESULTS AND DISCUSSIONS \\ 1. Microstructural Characterization of A2020-CNT MMCs using Optical Microscope}

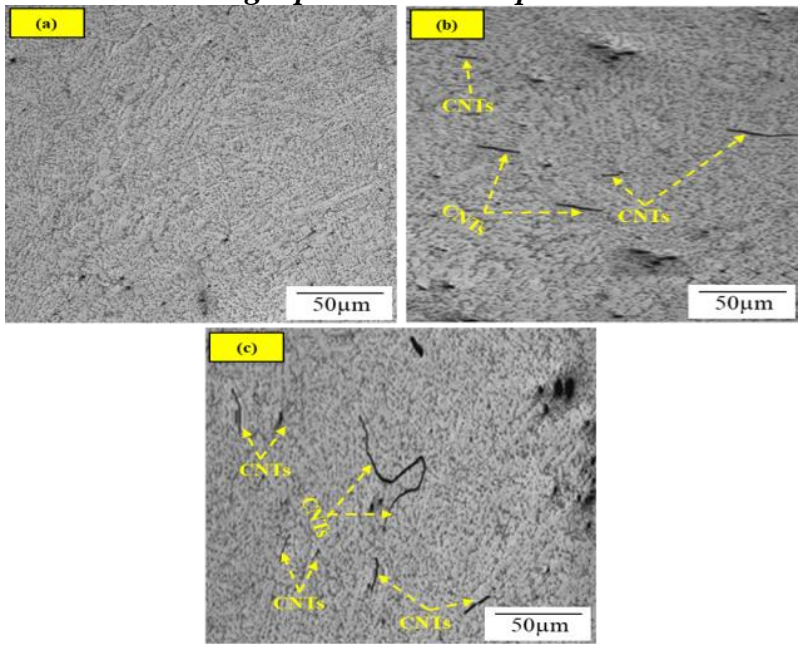

Figure 4.1: Microstructure Characterization of Al2020-CNTs MMCs using Optical Microscope, Where (a) Al2020 alloy (b) Al2020 alloy + 0.5\% CNT(c) Al2020 alloy + 1\% CNT

Figure 4.1 shows optical micrographs of Al2020 alloy and its CNT composites . Fig 4.1(a) shows the optical micrograph of Al2020 alloy which shows fine grains in the microstructure. From 5.1(b-c) shows the optical micrograph of A12020 alloy reinforced with $0.5 \%$ and $1 \%$ CNTs . From the micrographs we can see the even dispersal of CNTs in the Al2020 matrix. These observations are in accord with several investigators [9] .

\section{Hardness test results of A2020-CNT MMCs}

Table 4.1: Hardness test values of A2020-CNT composites

\begin{tabular}{|c|c|c|c|c|c|c|}
\hline \multirow[t]{2}{*}{$\mathbf{S}$} & \multirow{2}{*}{$\begin{array}{l}\text { Alloy/C } \\
\text { omposit } \\
\text { e }\end{array}$} & \multirow{2}{*}{$\begin{array}{l}\text { Desi } \\
\text { gnati } \\
\text { on }\end{array}$} & \multicolumn{3}{|c|}{ Hardness } & \multirow{2}{*}{$\begin{array}{l}\% \\
\text { Impr } \\
\text { ovem } \\
\text { ent } \\
\text { in } \\
\text { Hard } \\
\text { ness }\end{array}$} \\
\hline & & & $\begin{array}{l}\text { Load } \\
(\mathbf{K g})\end{array}$ & $\begin{array}{l}\text { Inden } \\
\text { tation } \\
\text { (m } \\
\text { m) }\end{array}$ & BHN & \\
\hline 1 & $\begin{array}{l}\mathrm{Al} 202 \\
0 \\
\text { alloy }\end{array}$ & Al2020 & 250 & $\begin{array}{l}2 . \\
1\end{array}$ & $\begin{array}{l}71 . \\
4\end{array}$ & -- \\
\hline 2 & $\begin{array}{l}\mathrm{A} 12020 \\
\text { alloy + } \\
0.5 \% \mathrm{CN} \\
\mathrm{T}\end{array}$ & $\begin{array}{l}0.5 \\
\% \\
\mathrm{CN} \\
\mathrm{T} \\
\end{array}$ & 250 & $\begin{array}{l}1 . \\
8\end{array}$ & $\begin{array}{l}97 . \\
4\end{array}$ & $\begin{array}{l}36.4 \\
1\end{array}$ \\
\hline 3 & $\begin{array}{l}\text { Al202 } \\
0 \\
\text { alloy } \\
+1 \% \\
\text { CNT }\end{array}$ & $\begin{array}{l}1 \% \\
\mathrm{CN} \\
\mathrm{T}\end{array}$ & 250 & $\begin{array}{l}1 . \\
6\end{array}$ & 123.5 & $\begin{array}{l}72.9 \\
6\end{array}$ \\
\hline
\end{tabular}




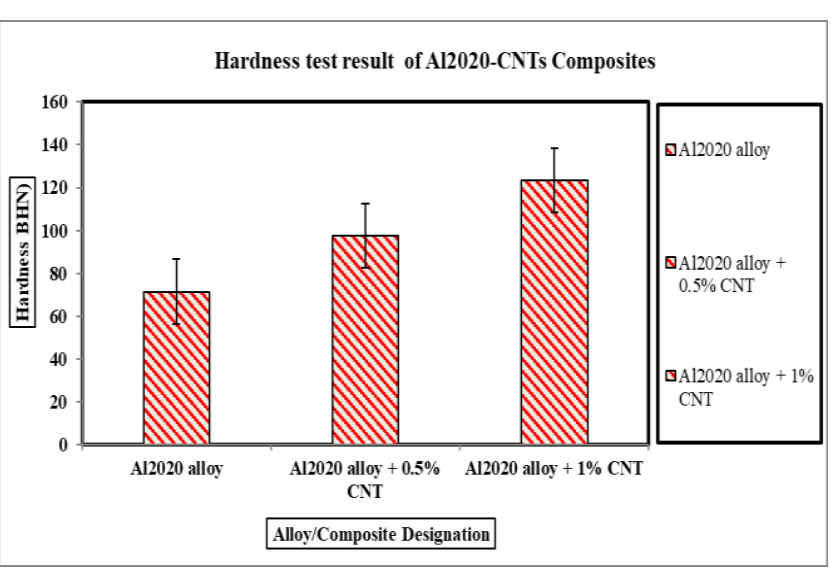

Figure 4.2: Hardness test values of Al2020-CNT composites

Figure 4.2 shows the Hardness test values of A12020 alloy and its composites. From the figure 5.2 we can see as the percentage of CNT increased hardness values increases. Compared to as-cast A12020 alloy the composite reinforced with $0.5 \% \mathrm{CNT}$ is increased by $36.41 \%$.Similarly the composite reinforced with $1 \% \mathrm{CNT}$ is increased by $72.96 \%$.The increase in hardness values of the composite was found to increase due even spreading of CNT reinforcement leading to improvement in hardness in the matrix [10]

3. Compression test results of A2020-CNT MMCs

\begin{tabular}{|c|c|c|c|c|c|c|}
\hline $\begin{array}{l}\mathbf{S} \\
/\end{array}$ & $\begin{array}{l}\text { Alloy/C } \\
\text { omposit }\end{array}$ & $\begin{array}{l}\text { Design } \\
\text { ation }\end{array}$ & $\begin{array}{l}\text { Ultimat } \\
\text { Stress }(\end{array}$ & $\begin{array}{l}\text { Compre } \\
\text { CS) }\end{array}$ & sion & $\begin{array}{l}\% \\
\text { Impr }\end{array}$ \\
\hline $\mathbf{N}$ & e & & $\begin{array}{l}\text { Strain } \\
\text { rate } \\
(\mathrm{mm} / \mathrm{s})\end{array}$ & $\begin{array}{l}\text { Stiffness } \\
\text { (kN/mm) }\end{array}$ & MPa & $\begin{array}{l}\text { ovem } \\
\text { ent in } \\
\text { Hard } \\
\text { ness }\end{array}$ \\
\hline 1 & $\begin{array}{l}\text { Al2020 } \\
\text { alloy }\end{array}$ & $\begin{array}{l}\mathrm{Al} 202 \\
0\end{array}$ & $\begin{array}{l}0.01 \\
000\end{array}$ & 36.141 & 80.45 & ---- \\
\hline 2 & $\begin{array}{l}\text { Al2020 } \\
\text { alloy }+ \\
0.5 \% \\
\text { CNT }\end{array}$ & $\begin{array}{l}0.5 \% \\
\text { CNT }\end{array}$ & $\begin{array}{l}0.01 \\
000\end{array}$ & 38.026 & 99.21 & 23.31 \\
\hline 3 & $\begin{array}{l}\text { Al2020 } \\
\text { alloy + } \\
1 \% \\
\text { CNT }\end{array}$ & $\begin{array}{l}1 \% \\
\text { CNT }\end{array}$ & $\begin{array}{l}0.01 \\
000\end{array}$ & 41.969 & 122.01 & 51.65 \\
\hline
\end{tabular}

Table 4.2: Compression test values of A2020-CNT composites

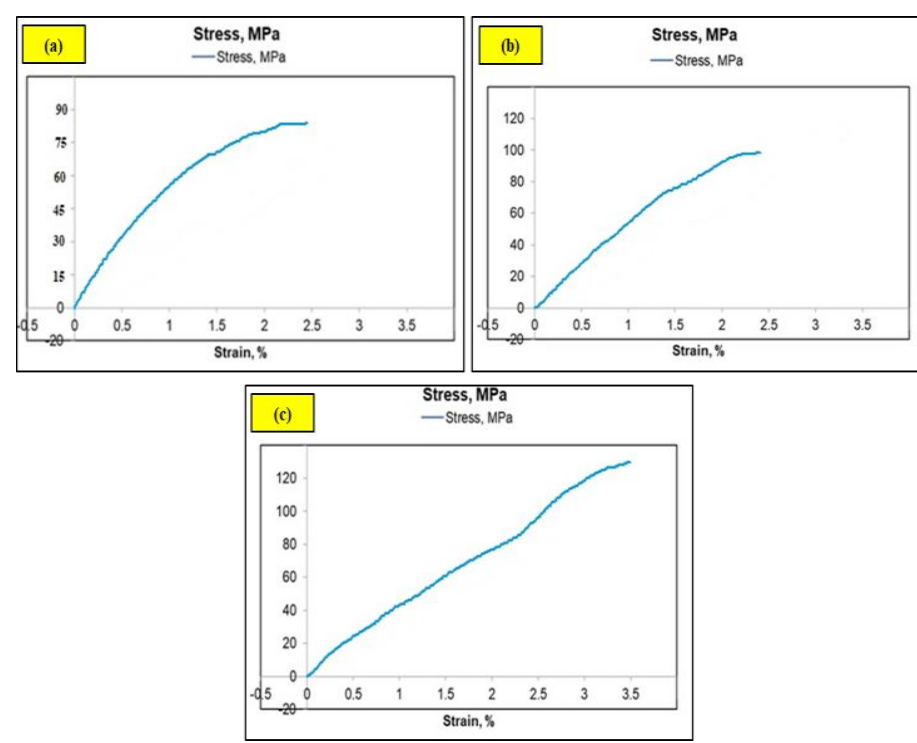

Figure 4.3.1: Compression test values of Al2020-CNT composites, where (a) Al2020 alloy (b) Al2020 alloy $+0.5 \%$ CNT(c) Al2020 alloy $+1 \%$ CNT

Figure 4.3.1 shows the stress -strain curve of A12020 alloy and its composites. From the figure we can see the stress values of Al2020 alloy of $80.45 \mathrm{MPa}$, stress values of A12020 alloy + $0.5 \% \mathrm{CNT}$ of $99.21 \mathrm{MPa}$ and stress values of A12020 alloy $+1 \%$ CNT of 122.01 MPa.

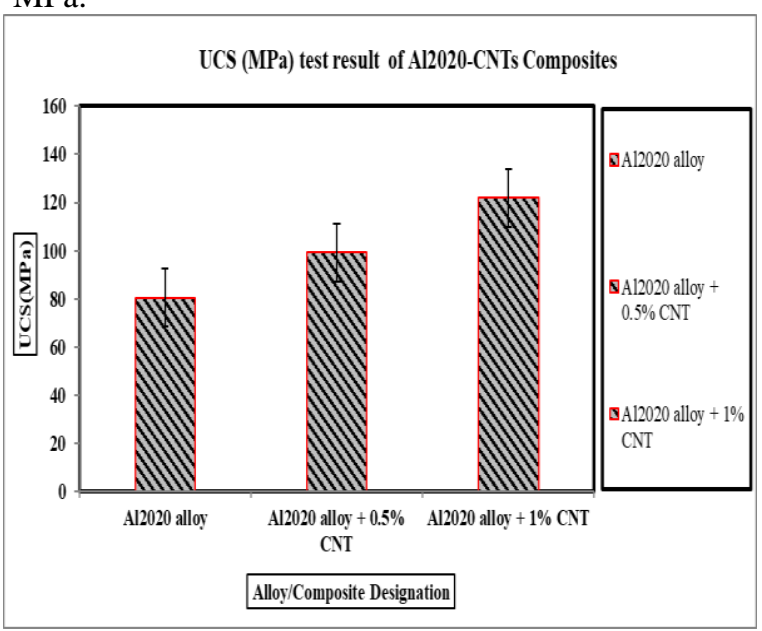

Figure 4.3.2: Compression test values of Al2020-CNT composites

Figure 4.3.2 shows the compression test values of Al2020 alloy and its composites. From the figure 4.3.2 we can see as the percentage of CNT increased compression values increases. Compared to as-cast Al2020 alloy the composite reinforced with $0.5 \%$ CNT is increased by $23.31 \%$.Similarly the composite reinforced with $1 \% \mathrm{CNT}$ is increased by $51.65 \%$. The increase in compression values of the composite was found to increase due even spreading of CNT reinforcement and also due to the hardening of the base alloy due to CNT particles [11] . 


\begin{tabular}{|c|c|c|c|c|}
\hline \multicolumn{5}{|c|}{ Wear rate of A2020-CNT composites } \\
\hline $\begin{array}{l}\mathbf{S} \\
/ \\
\mathbf{N} \\
0\end{array}$ & $\operatorname{Load}(\mathbf{N})$ & 10 & 20 & 30 \\
\hline 1 & $\begin{array}{l}\text { Al2020 } \\
\text { alloy }\end{array}$ & $\begin{array}{l}0.922 \\
3 \\
\end{array}$ & 0.9251 & 0.9295 \\
\hline 2 & $\begin{array}{l}\text { Al2020 } \\
\text { alloy } \\
0.5 \% \\
\text { CNT }\end{array}+$ & $\begin{array}{l}0.740 \\
1\end{array}$ & 0.7423 & 0.7465 \\
\hline 3 & $\begin{array}{l}\mathrm{Al} 2020 \\
\text { alloy + } \\
1 \% \mathrm{CNT}\end{array}$ & $\begin{array}{l}0.621 \\
1\end{array}$ & 0.6257 & 0.6291 \\
\hline
\end{tabular}

Table 4.3: Wear test values of A2020-CNT composites

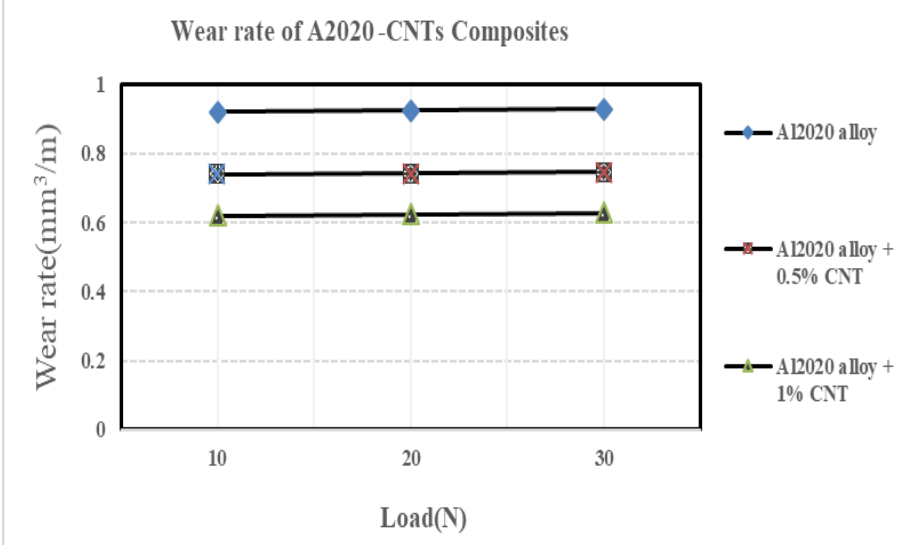

Figure 4.4: Wear test values of Al2020-CNT composites

From Figure 4.4 we can see that as the load increases the wear rate increases. Highest wear rate is for A12020 alloy i.e. $0.9223 \times 10^{-3} \mathrm{~mm}^{3} / \mathrm{m}$ for $10 \mathrm{~N}$ and $0.9295 \times 10^{-3} \mathrm{~mm}^{3} / \mathrm{m}$ for $30 \mathrm{~N}$ respectively . Moderate wear rate is found for Al2020 alloy $+0.5 \%$ CNT i.e. $0.7401 \times 10^{-3} \mathrm{~mm}^{3} / \mathrm{m}$ for $10 \mathrm{~N}$ and $0.7465 \times 10^{-3}$ $\mathrm{mm}^{3} / \mathrm{m}$ for $30 \mathrm{~N}$ respectively .Least wear rate is found for Al2020 alloy $+1 \%$ CNT i.e. $0.6211 \times 10^{-3} \mathrm{~mm}^{3} / \mathrm{m}$ for $10 \mathrm{~N}$ and $0.6291 \times 10^{-3} \mathrm{~mm}^{3} / \mathrm{m}$ for $30 \mathrm{~N}$ respectively. CNT particles act as load bearing and protect matrix from wearing out [11] .

\subsection{Wear surface Morphology of A2020-CNT MMCs}

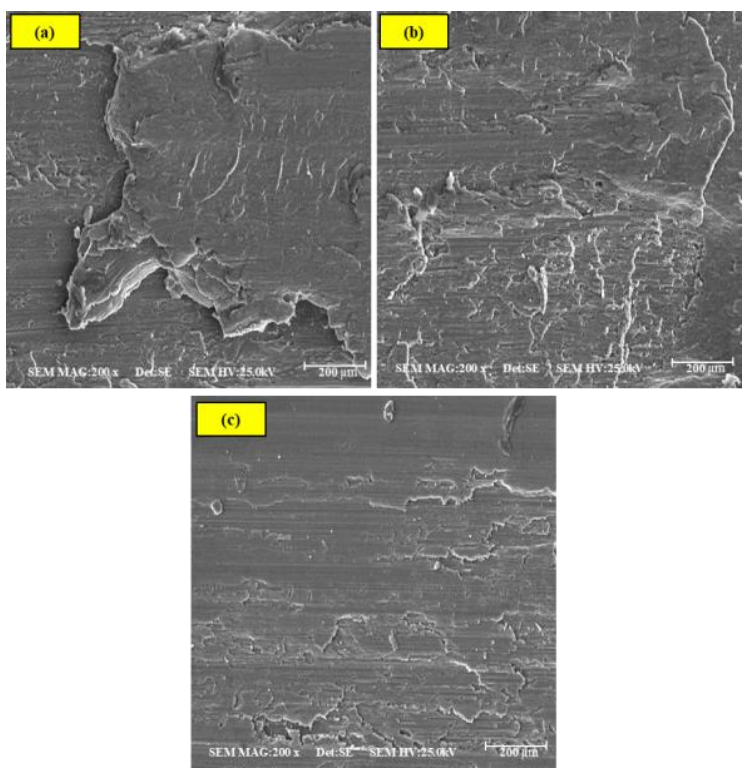

Figure 4.5: Wear Surface Morphology of Al2020-CNT composites at a load of $30 \mathrm{~N}$ where (a) Al2020 alloy (b) Al2020 alloy $+0.5 \%$ CNT(c) Al2020 alloy $+1 \%$ CNT

Figure 4.5 shows the wear surface morphology of A12020 alloy and its composites at a load of 30N. From the figure 4.5 we can see that wear surface morphology of A12020 alloy has a rough surface and more surface delamination. Also, we can see that there is a greater extent of plastic deformation on the surfaces. Whereas wear surface morphology of Al2020 composites $(0.5 \%$ and $1 \%$ CNT) has a relatively smoother surface with less surface delamination and lesser extent of plastic deformation [12]

\section{CONCLUSIONS}

From the tests to understand the mechanical behavior of Carbon nanotube (CNT) reinforced A12020 composites of different weight fractions of the reinforcement, it was found that:

(i) The Optical Micrographs of polished specimens, the following was observed:

$>$ The spreading of Carbon nanotube (CNT) is found to be even in Al2020 alloy matrix

$>$ The Carbon nanotube (CNT) Particles acted as virtuous moistening with the Al2020 matrix which added to the enhancements of the mechanical and wear properties.

(ii) Carbon nanotube (CNT) particles as a reinforcement abetted in increasing the hardness (BHN) of Al2020 from 71.4 (BHN) as per the following:

$>0.5 \%$ Carbon nanotube (CNTs) - 97.4(BHN) (36.41\% increase)

$>1 \%$ Carbon nanotube (CNTs) -123.5 (BHN) (72.96\% increase)

(iii) Carbon nanotube (CNT) particles as a reinforcement assisted in increasing the UCS $(\mathrm{MPa})$ of 
Al2020 from $80.45 \mathrm{MPa}$ as per the following:

$>0.5 \%$ Carbon nanotube (CNTs) - $99.21 \mathrm{MPa}$ (23.31\% increase)

$>0.5 \%$ Carbon nanotube (CNTs) $-122.01 \mathrm{MPa}$ (51.65\% increase)

(iv) Wear surface morphology of A12020 alloy shows rough surface with more trenches and crests compared to wear surface morphology of A12020 -CNTs composites

\section{ACKNOWLEDGMENT}

We are thankful to Department of Mechanical Engineering ,Nitte Meenakshi Institute of Technology, Bengaluru for constant encouragement and support.

\section{REFERENCES}

[1] L Avinash, T Ram Prabhu, S Bontha "The Effect on the dry sliding wear behavior of gravity cast A357 reinforced with dual sizesilicon carbide particles" Applied Mechanics and Materials,829,(2016),83-89.

DOI :https://doi.org/10.4028/www.scientific.net/AMM.829.83

[2] B Sajjan, L Avinash, S Varun, KN Varun Kumar, A Parthasarathy "Investigation of Mechanical Properties and Dry Sliding Wear Behaviour of Graphite Reinforced A17068 Alloy "Applied Mechanics and Materials ,867,(2017), 10-18 DOI :https://doi.org/10.4028/www.scientific.net/AMM.867.10

[3] L Avinash, T Ram Prabhu, A Parthasarathy, KN Varun Kumar, B Sajjan " Wear and mechanical behaviour of Hypoeutectic $\mathrm{Al}-7 \% \mathrm{Si}-0.5 \% \mathrm{Mg}$ alloy (A357) reinforced with $\mathrm{Al}_{2} \mathrm{O}_{3}$ particles", Applied Mechanics and Materials $, 829,(2016)$,

$66-72$ DOI: https://doi.org/10.4028/www.scientific.net/AMM.829.66

[4] A Parthasarathy, L Avinash, KN Varun Kumar, B Sajjan, S Varun "Fabrication and Characterization of $\mathrm{Al}-0.4 \% \mathrm{Si}-0.5 \%$ Mg-SiCp Using Permanent Mould Casting Technique "Applied Mechanics and Materials, 867,(2017),34-40, https://doi.org/10.4028/www.scientific.net/AMM.867.34

[5] L Avinash, H Kumar, A Parthasarathy, KN Varun Kumar, B Sajjan, "The Effect of Ceramic Reinforcement on the Microstructure, Mechanical Properties and Tribological Behavior of Al-7.5\% Si-0.5\% Mg Alloy" Applied Mechanics and Materials, 867,(2017),3-9, https://doi.org/10.4028/www.scientific.net/AMM.867.3

[6] Avinash Lakshmikanthan, T. Ram Prabhu, Udayagiri Sai Babu, Praveennath G. Koppad, Manoj Gupta, Munishamaiah Krishna , Srikanth Bontha (2020) "The effect of heat treatment on the mechanical and tribological properties of dual size $\mathrm{SiC}$ reinforced A357 matrix composites" Journal of Materials Research and Technology, Volume 9, Issue 3, May June 2020, Pages 6434-6452

[7] Benyamin Abbasipour, Behzad Niroumand, Sayed Mahmoud Monir Vaghefi, Mohammad Abedi. "Tribological behavior of A356-CNT nanocomposites fabricated by various casting techniques". Trans. Nonferrous Met. Soc. China 29(2019) 1993-2004.

[8] Omkar Aranke, Chaitanya Gandhi, Nikhil Dixit, P. Kuppan. "Influence of Multiwall Carbon Nanotubes (MWCNT) on Wear and Coefficient of Friction of Aluminium (Al 7075) Metal Matrix Composite". Materials Today: Proceedings (2018) 7748-7757.

[9] S.M. Towhidul Islam Nayim, Muhammed Zahid Hasan, Prem Prakash Seth, Pallav Gupta, Sunil Thakur, Devendra Kumar, Anbesh Jamwal. "Effect of $\mathrm{CNT}$ and $\mathrm{TiC}$ hybrid reinforcement on the micro-mechano-tribo behaviour of aluminium matrix composites". Materials Today: Proceedings Volume 21, Part 3, 2020, Pages 1421-1424.

[10] Bandil K, Vashisth H, Kumar S, Verma L, Jamwal A, Kumar D "Microstructural, mechanical and corrosion behaviour of Al-Si alloy reinforced with $\mathrm{SiC}$ metal matrix composite". J
Comp Mater 2019

[11] Jamwal A, Vates UK, Gupta P, Aggarwal A, Sharma BP. "Fabrication and characterization of $\mathrm{Al}_{2} \mathrm{O}_{3}$-TiC-reinforced aluminum matrix composites. In: Advances in industrial and production engineering. Singapore": Springer; 2019. p. 34956.

[12] Yadav Shiv Pratap Singh, Ranganath S., Sharieff Salim, Suresh R., Avinash L "Investigations on the change in state of stress with respect to the sliding direction in dry sliding wear of hard elastic material with different geometry and orientation on ductile flat surface ,FME Transactions,2020, vol. 48, br. 3 , str. 716-723 